\title{
INVESTIGACIONES
}

\section{Construyendo un aprendizaje significativo a través del patrimonio local: prácticas de Educación patrimonial en Portugal y Brasil*}

\author{
Constructing a significant learning through local heritage: \\ practicing Heritage Education in Portugal and Brazil
}

\author{
Helena Pinto, ${ }^{a}$ Jaqueline Zarbato ${ }^{b}$ \\ ${ }^{a}$ Centro de Investigação Transdisciplinar Cultura, Espaço e Memória \\ Facultade de Letras, Universidade do Porto \\ Correo electrónico: mhelenapinto@gmail.com \\ bLaboratorio de Educación Histórica y del área PIBID, Universidad Federal de Mato Grosso do Sul \\ Correo electrónico: jaqueline.zarbato@gmail.com
}

\begin{abstract}
RESUMEN
En este artículo se plantea presentar una aproximación al patrimonio cultural en que se combinan teoría y práctica a la luz de la metodología de investigación en educación patrimonial y en la didáctica de la historia, con el objetivo de analizar y comprender cómo en dos países diferentes, Portugal y Brasil, la implementación de actividades de enseñanza y aprendizaje de historia con exploración del patrimonio cultural en ámbito local, favorece la progresión en el conocimiento histórico y en la conciencia patrimonial de los estudiantes. Se refieren las principales líneas del debate teórico (desde los referentes anglosajones e ibéricos a los latinoamericanos) que fundamentan la metodología utilizada. Seguidamente, se describen dos estudios de caso que se han desarrollado en el ámbito de educación formal con estudiantes de $7^{\circ}$ grado en el norte de Portugal y estudiantes de $8^{\circ}$ grado en el centro-oeste de Brasil, planteando conocer las concepciones de los estudiantes hacia diversas huellas del patrimonio cultural de su entorno. Los resultados de las experiencias educativas desarrolladas en contextos diferentes, si bien sin objetivos comparativos, muestran que muchos de los estudiantes han superado sus concepciones previas y algunos revelan conciencia histórica respecto al uso de ese patrimonio cultural. Por consiguiente, hay potencial para la interpretación de las fuentes patrimoniales, materiales o inmateriales en la educación, mientras se estimule a los jóvenes a pensar críticamente sobre su entorno y la relación con los demás.
\end{abstract}

Palabras clave: educación formal, educación patrimonial, patrimonio, memoria, identidad, conciencia histórica.

\section{ABSTRACT}

This paper proposes to present an approach to cultural heritage where theory and practice are mixed in the light of the research methodology in heritage education and history education, aiming to analyse and understand, in two different countries, Portugal and Brazil, how does the implementation of history teaching and learning activities with exploration of local cultural heritage, improves students' progression in historical understanding and heritage awareness. The main lines of the theoretical debate (from Anglo-Saxon and Iberian to Latin Americans references) are described, as they support the methodology structuring this study.

Subsequently, we describe two case studies which have been developed in the area of formal education, with 7th grade students, in the north of Portugal, and 8th grade students, in the centre-west of Brazil, intending to

Trabalho cofinanciado pelo Fundo Europeu de Desenvolvimento Regional (FEDER) através do COMPETE 2020-Programa Operacional Competitividade e Internacionalização (POCI) e por fundos nacionais através da FCT, no âmbito do projeto POCI-01-0145-FEDER-007460. 
Estudios Pedagógicos XLIII, N 4: 203-227, 2017

CONSTRUYENDO UN APRENDIZAJE SIGNIFICATIVO A TRAVÉS DEL PATRIMONIO LOCAL: PRÁCTICAS DE EDUCACIÓN PATRIMONIAL EN PORTUGAL Y BRASIL

understand students' conceptions about diverse cultural heritage traces in their social geographic environment. The results of the educational experiences, developed in different contexts, although without comparative objectives, revealed that many of the students have surpassed their previous conceptions and some of them revealed historical awareness regarding the use of the observed cultural heritage. Accordingly, there is potential for the interpretation of heritage sources in education, once encouraging young people to reason critically about their environment and the relationship with others.

Keywords: formal education, heritage education, heritage, memory, identity, historical consciousness.

\section{INTRODUCCIÓN}

Una de las características que más se destacan en la reflexión sobre el concepto de patrimonio es la temporalidad. El patrimonio es un espejo de los varios tiempos en una comunidad; es expresión de su cultura, de sus especificidades, por lo que es un factor de identidad. La relación entre la problemática de la identidad y del patrimonio pone de relieve la conciencia de que ambos se organizan alrededor del tema de las relaciones con el lugar y el tiempo. Según Pomian (1998), si conservamos el patrimonio cultural, es decir, el conjunto de objetos, naturales o artificiales, extraídos en parte o en su totalidad del circuito de las actividades de uso cotidiano, a fin de que sean conservados para un futuro lejano, hacemos visible la conexión con el pasado.

Muchos de los estudios desarrollados en las últimas décadas, subrayando las obras de Lowenthal (1999, 2003), insisten en que lo que llamamos 'patrimonio' es una reconstrucción del pasado en la sociedad del presente a fin de comprender valores e identidades que enlazan el pasado y el presente. Según Colardelle (1998), tres pasos señalan, por lo general, el surgimiento de un patrimonio: el primero, espontáneo, es aquel en que la sociedad produce lo que necesita; el segundo es el surgimiento de una conciencia respecto a una mutación que excede el campo utilitario inicial del objeto; el tercero es que el objeto logra una identidad patrimonial. La idea patrimonial surge en la charnela entre la segunda y la tercera etapa.

La entrada en la era industrial ha creado, según Choay (2000), una mediación y un distanciamiento hacia el monumento histórico, mientras impulsaba su protección. Poco a poco se ha verificado una extensión triple -tipológica, cronológica y geográfica- de los bienes patrimoniales. Diversas convenciones internacionales -subrayando la Convención sobre la Protección del Patrimonio Mundial Cultural y Natural, Paris, 1972- vienen coordinando este movimiento, verificándose todavía alguna distancia entre los principios y su cumplimiento. La atención centrada inicialmente en los monumentos históricos se extendió a nuevos enfoques culturales y ambientales, y a lo intangible, estableciéndose nuevos usos del patrimonio. Junto a la mundialización se ha fortalecido la protección a nivel nacional y local, revelando la necesidad de hallar los rasgos distintivos, las identidades.

El patrimonio se ha convertido en un tema dominante en la vida cultural y en las políticas públicas. A menudo, los debates sobre el patrimonio expresan ideas nostálgicas de memorias colectivas centradas en la continuidad. Sin embargo, las características culturales de las sociedades cambian, a diferentes ritmos, llevando a la desaparición elementos hasta entonces familiares, como saberes-hacer y paisajes construidos o naturales. En estos momentos puede producirse una toma de conciencia patrimonial. Por eso es esencial reflexionar sobre las formas en que el patrimonio se relaciona con la memoria y la historia, sobre todo en las sociedades occidentales, pues de ello depende en 
gran medida que se desarrolle una perspectiva más cerrada o más inclusiva e histórica de esa relación (Pinto, 2011).

\section{PATRIMONIO, MEMORIA E IDENTIDADES}

La noción de patrimonio como significado de memoria colectiva y presentada como un legado del pasado al presente y al futuro ha sido señalada por algunos autores como Nora (1997), Yáñez Casal (1999) y Hartog (2005). Según este último, la búsqueda de identidad en la continuidad entre "nuestros antepasados" y "nosotros" ha caracterizado al régimen de historicidad anterior, pero la demanda de alteridad y la discontinuidad entre el pasado y el presente caracteriza el "régimen de historicidad" del presente (Hartog, 2005). Para estos autores, basándose en una concepción lineal y tradicional del tiempo y de la historia, la memoria, "vivificada" en el patrimonio, haría la conexión entre el pasado y el presente. Sin embargo, el patrimonio no puede mirarse solamente como reserva o recuerdo, sino como parte de nuestro presente (Pinto, 2011).

Otros autores han puesto de manifiesto la distinción entre la memoria y la historia, considerando que la primera, reinterpretada por la acción retrospectiva, sirve de modelo al conocimiento histórico (Ricoeur, 2000) y desarrolla su función social a través de "liturgias propias" centradas en suscitaciones que solamente los rastros de lo que ya no existe permiten provocar (Catroga, 2009, p. 21). Otros consideran aún que la memoria es un vestigio del pasado visto en su relación con la temporalidad: mientras que para la actitud memorial el patrimonio es un conjunto de recuerdos materializados en un territorio y susceptibles de evocar recuerdos interiorizados por los individuos, para la actitud historiográfica el patrimonio es un conjunto de huellas del pasado que devienen objeto de conocimiento (Pomian, 1998). Así que para comprender el patrimonio y los problemas que plantea necesitamos tener en cuenta su temporalidad intrínseca, que sirve como evidencia para las cuestiones de los historiadores (Pinto, 2011).

Collingwood (2001) y Halbwachs (1990) pusieron de relieve la dicotomía entre la memoria -de la experiencia vivida- e Historia -fundada en la crítica-. La primera se basa en el recuerdo que es en gran parte una reconstrucción del pasado con auxilio de datos del presente y reconstrucciones de épocas anteriores. Esta oposición excluye la posibilidad de que la memoria colectiva y la historia se confundan, pues la historia pone de relieve las diversas características de un grupo, los cambios a lo largo del tiempo, mientras que la memoria colectiva establece la continuidad del grupo. Lowenthal (1999) considera que conocemos el pasado porque recordamos las cosas, leemos o escuchamos historias y vivimos con las huellas tangibles de épocas anteriores. Si bien toda la acción humana tiene contenido residual de otros tiempos, no se puede evitar reconstruir el pasado cambiando y añadiendo algo, y eso es lo que mantiene el patrimonio "real, viviente y comprensible" (Lowenthal, 1999, p. 411). Cuando tengamos conciencia de que el pasado y el presente no son excluyentes, dejaremos de insistir en la preservación de un pasado fijo y estable (Lowenthal, 2003). Es en esta perspectiva de atención a la temporalidad histórica que se considera, en esta investigación, la memoria (ya sea en forma de narrativa, o de objetos conmemorativos, u otros vestigios materiales mediadores entre el pasado y el presente), como una fuente histórica para la construcción de conocimiento sobre el pasado (Pinto, 2011), interpretándola como evidencia mediante una metodología científica específica, y no como el pasado en sí mismo. 
Estudios Pedagógicos XLIII, N 4: 203-227, 2017

CONSTRUYENDO UN APRENDIZAJE SIGNIFICATIVO A TRAVÉS DEL PATRIMONIO LOCAL: PRÁCTICAS DE EDUCACIÓN PATRIMONIAL EN PORTUGAL Y BRASIL

\subsection{PATRIMONIO LOCAL Y CONCIENCIA PATRIMONIAL}

La conexión con un evento histórico importante o el prestigio de un monumento fueron inicialmente criterios esenciales para la preservación del patrimonio; los criterios científicos arqueológicos y las razones económicas de la promoción turística llegaron más tarde. Se defiende generalmente lo que se conoce o lo que se valora, pero estos dos aspectos no siempre están conectados. El vínculo natural de los habitantes a un lugar puede deberse a que estén cercanos en el espacio (Halbwachs, 1990) y la valoración resultar de la naturaleza simbólica asignada por la comunidad a un patrimonio.

En casi todos los espacios, sean urbanos o rurales, hay huellas de la actividad humana en el pasado. La toponimia, por ejemplo, es crucial para la comprensión de los espacios urbanos antiguos, sobre todo cuando los restos materiales ya no son visibles. Recorrer la toponimia permite redescubrir las actividades cotidianas y acercarnos a las dinámicas económicas, sociales, religiosas y culturales de las comunidades. Muchos topónimos de las áreas urbanas con traza medieval, por ejemplo, revelan que gran parte de la población se dedicaba a la actividad artesanal desarrollada generalmente en su residencia, que tenía igualmente la función de taller y de tienda. En Guimarães (norte de Portugal, referente al primer caso estudiado) eso sería común en la calle Sapateira, así como en las calles Forja, Ferraría y Caldeiroa. La toponimia permite también ordenar y señalar la especialización de ciertas áreas de negocio (Andrade, 1993). Las calles Sapateira y Mercadores -hoy calle Rainha D. Maria II- han sido los accesos principales de la plaza de Santa María. Allí se situaban los establecimientos de los comerciantes más importantes: sastres, orfebres, carpinteros, zapateros (Ferreira, 2010).

En los arrabales se ubicaban establecimientos de tratamiento de las pieles: en la calle Couros se concentraban los que se dedicaban a la curtiduría, labor importante pero maloliente. Hay registro documental desde 1096, en la carta de fuero concedida por el Conde D. Henrique, que mencionaba pieles de conejo, buey y vaca (Ferreira, 2010). Siendo los sastres y los zapateros los oficios de mayor peso socio-profesional, no es extraño que hayan sido los primeros en disfrutar de una cofradía artesanal en Guimarães, respectivamente en 1241 y 1243. La importancia de las curtidurías se ha mantenido más allá de la Edad Media y la identidad del barrio ha permanecido en el topónimo Couros referente a la calle y al arroyo que la cruza, aunque muchos rastros de la actividad artesanal hayan desaparecido. Este barrio ha registrado el mayor crecimiento industrial, especialmente durante el siglo XIX. En el Informe de la Exposición Industrial de Guimarães de 1884, la industria de curtiduría fue considerada la más importante en valor de producción y capital disponible (Sampaio \& Meira, 1991). Hasta mediados del siglo XX, siguieron trabajando algunas unidades industriales en las curtidurías, donde las prácticas ancestrales se conjugaban con alguna innovación técnica. En 1977, el núcleo industrial ha sido clasificado de interés público por la Dirección General de Patrimonio Cultural y actualmente está en curso la solicitud de ampliación de la clasificación Patrimonio Cultural de la Humanidad a esta área.

Entender los edificios, las calles, los saberes culturales como elementos patrimoniales impulsa a que las personas accedan a los bienes patrimoniales. Esto es también lo que se ha pretendido con el segundo caso aquí presentado ${ }^{1}$, en el contexto brasileño, más precisamente

El proyecto de investigación "Recontando a História de Três Lagoas/MS: narrativas e utilizações da Educação Patrimonial nas aulas de História”, se está desarrollando desde el año 2014 y tiene como becario al investigador Caio Santos. 
en Três Lagoas, ciudad del estado de Mato Grosso do Sul, fundada a principios del siglo XX. Esta ciudad del interior tuvo como impulso social y económico la construcción del ferrocarril "Noroeste do Brasil" en 1914. Gran parte de su patrimonio clasificado como histórico está, directa o indirectamente, vinculado al ferrocarril, como es el caso del barrio Santa Luzia, que albergaba a los trabajadores ferroviarios.

Algunas de sus características sociales tienen origen en el período de su formación, como por ejemplo el movimiento de las personas, pues era una ciudad de paso. Por eso, la fundamentación e identidades están directamente vinculadas a la ferrovía, que funciona como un depósito de elementos culturales que corporizan los significados del patrimonio para la ciudad y para las personas. Sin embargo, después de la construcción del puente Francisco de Sá en el río Paraná, conectando los estados de São Paulo y de Mato Grosso, en 1926, el flujo de personas en Três Lagoas disminuyó (Mendonça, 1991). La historia de la construcción de la estación ferroviaria en Três Lagoas y su representación cultural para los habitantes de la ciudad tiene una importancia histórica, pues ha sido gracias a ese elemento patrimonial que toda la ciudad se ha estructurado: la plaza de la bandera, la iglesia matriz, las calles alrededor de la estación, el barrio de los ferrocarrileros. En estos espacios, que se constituyeron a partir de la construcción de la estación, las acciones de los habitantes ganaron otras dimensiones en la ciudad, como la circulación de mercancías y de personas de diferentes lugares, recaudando a la estación el status de representatividad patrimonial de la ciudad. Es este significado histórico lo que intentamos investigar con los estudiantes (Zarbato \& Santos, 2015).

\subsection{CONCIENCIA HISTÓRICA Y EDUCACIÓN PATRIMONIAL}

Así como el patrimonio, la conciencia histórica es una construcción simbólica y, al igual que la identidad, lleva a cabo un proceso de apropiación simbólica de lo real.

La conciencia histórica, según Rüsen (2001), incluye las operaciones mentales emocionales y cognitivas, conscientes e inconscientes- a través de las cuales el tiempo experimentado en forma de memoria es utilizado como medio de orientación en la vida práctica. Así, la conciencia histórica no reduce el tiempo con significado al pasado, excede sus dimensiones. La historia, como contenido de la conciencia histórica, es una relación entre presente y futuro, surge con y en el pasado recordado. La conciencia histórica también es estimulada e influenciada por las experiencias en el presente, por lo que su función para atribuir significado depende en gran medida del contexto en que se produce: parte del presente hacia el pasado y vuelve al presente con experiencias para revelar el futuro como referencia de acción (Rüsen, 2001). Esa referencia al futuro está implícita en la interpretación histórica del presente, pues debe permitirnos actuar, es decir, facilitar la dirección de nuestras intenciones en una matriz temporal, una concepción del curso del tiempo que fluye en las vicisitudes de la vida cotidiana, guiando la acción. La orientación temporal en la vida y la identidad histórica constituyen las dos funciones esenciales de la conciencia histórica (Rüsen, 2001), concretizándose en una diversidad de posibilidades de acuerdo con cuatro principios de orientación temporal: afirmación de orientaciones establecidas; regularidad de patrones culturales y de vida; negación; y transformación de patrones de orientación. Todos ellos surgen por acción de la memoria histórica y estructuran los procedimientos para dar sentido histórico al pasado.

El aprendizaje es, según Rüsen (2004), una calidad específica de los procedimientos mentales de la conciencia histórica. El aprendizaje histórico implica algo más que la 
simple adquisición de conocimientos del pasado y el aumento de ese conocimiento. Visto como un proceso en el cual se adquieren gradualmente habilidades, emerge del cambio de las formas estructurales a través de las cuales usamos y lidiamos con la experiencia y el conocimiento de la realidad pasada, progresando "desde las formas tradicionales de pensamiento hacia las ontogenéticas" (p. 81). El aprendizaje de la historia se modifica en la medida que el contenido de la conciencia histórica es reconocido como un producto de la actividad mental. Así la conciencia histórica se convierte en una de las categorías clave de la didáctica de la historia (Rüsen, 2001).

A través de la cultura histórica, las funciones y las prácticas de la vida social se conectan a los elementos subjetivos de la conciencia en el ámbito de la didáctica de la historia (Rüsen, 2014). Por esta vía, la educación histórica añade la complejidad del análisis de la formación de significado, como señala Rüsen (2014) al referirse a las dimensiones de las prácticas culturales y sus narrativas.

Investigar las dimensiones del patrimonio y la relación con el aprendizaje histórico implica prácticas educativas que contribuyen al reconocimiento de la diversidad cultural en el mundo en que vivimos, donde cada manifestación cultural tiene significación social (Horta, Grunberg \& Monteiro, 1999). En la investigación sobre la importancia del patrimonio cultural en la enseñanza de la historia, incluyendo la necesidad de fundamentar prácticas de conservación de elementos patrimoniales, se entiende el concepto de patrimonio no como un elemento homogeneizador de las prácticas culturales, sino como un referente histórico relacionado con la memoria de los diferentes grupos y su contribución en la historia de las personas, de las ciudades y de los propios estudiantes, ya que reconocer los espacios históricos y relacionarlos con su vida contribuye a la formación de la conciencia histórica.

Sin embargo, y a pesar de los progresos recientes, el patrimonio aún es visto a menudo como un elemento decorativo o de prestigio. Numerosas depredaciones patrimoniales quedan por sancionar, y no se ha desarrollado con el cuidado merecido una conciencia informada, capaz de actuar en una sociedad abierta y global. Para que esto suceda, con más consistencia y en un futuro próximo, es necesario desarrollar una conciencia histórica y patrimonial en niveles más elaborados (Pinto, 2011), particularmente junto a los jóvenes.

Promover la conservación sostenible y la valoración de los bienes culturales en el ámbito de la enseñanza de la historia requiere actividades educativas que promuevan en el entorno escolar la oportunidad de lectura de la memoria colectiva, de los monumentos y de las relaciones que se establecen entre ellos, de forma analítica y crítica (Horta et al., 1999), y estos son, en gran parte, los objetivos de la Educación patrimonial.

\section{ENSEÑAR CON EL PATRIMONIO PARA UN APRENDIZAJE SIGNIFICATIVO}

Enseñar implica no solamente tener conocimiento de la ciencia específica, sino también de la psicología educativa, o sea, la manera en que aprende el estudiante. La investigación en psicología educativa, desde el punto de vista del constructivismo iniciado por Vigotski, ha desarrollado la teoría del aprendizaje significativo, según la cual para aprender es necesario relacionar los nuevos aprendizajes con las ideas previas (Ausubel, Novak \& Hanesian, 1978). Desde esta perspectiva el aprendizaje es un proceso de contraste, de modificación de los esquemas de conocimiento, de equilibrio, de conflicto y de nuevo equilibrio. Según Ausubel, Novak y Hanesian (1978), el proceso de adquisición de información produce una 
modificación tanto en la información adquirida como en la estructura cognoscitiva con la cual se relaciona.

En este aprendizaje por construcción los conceptos se van ajustando en la estructura cognitiva del alumnado, permitiendo que aprenda a aprender. Podemos decir que se produce aprendizaje significativo si los recursos utilizados están relacionados de manera no arbitraria en la estructura cognoscitiva del alumnado. Inversamente, los aprendizajes por repetición son entidades aisladas, desconectadas y dispersas en la mente del alumnado, que no permiten establecer relaciones en su estructura cognoscitiva. Juntamente con las ideas constructivistas y epistemológicas de la naturaleza del conocimiento, son necesarias sólidas prácticas de enseñanza basadas en la investigación para que se cumpla un aprendizaje significativo.

En cuanto a la historia como ciencia, Collingwood (2001) describió la historia constructiva como la interpretación de las afirmaciones que pueden deducirse de otras hechas por las fuentes, considerando que "la interpolación no es arbitraria o puramente imaginativa" (p. 252). Afirmaba que la imaginación es esencial para percibir el mundo que nos rodea, y lo es también para la historia. La imaginación histórica difiere de la "imaginación pura o libre del artista" y de la "imaginación perceptiva", no por ser apriorística, sino que por tener como tarea especial la de imaginar el pasado: "no un objeto de posible percepción, puesto que él ya no existe, pero propenso a convertirse, a través de la imaginación histórica, en un objeto de nuestro pensamiento" (p. 253). Así, el pensamiento histórico es la actividad de la imaginación que utiliza el presente como evidencia de su pasado.

Si es importante que los estudiantes conozcan bien alguna historia sustantiva, tengan bases seguras de conocimiento factual y conceptual y comprendan los contenidos en un marco más amplio, la comprensión de la historia también implica conceptos de otro tipo, generalmente conocidos como "meta-históricos", "de segundo orden" o "disciplinares" (Lee, 2005, p. 32). Estos conceptos, por ejemplo evidencia histórica, están involucrados en cualquier historia. Otros conceptos (por ejemplo nación, esclavo, tratado, entre otros) se refieren a tipos específicos de contenido histórico como parte de lo que llamamos la sustancia de la historia y, por eso, es natural llamarlos "conceptos sustantivos" (Lee, 2005, p. 61). Así, son los conceptos meta-históricos (por ejemplo evidencia, cambio, empatía, significancia) los que dan forma a la comprensión de lo que es "hacer" historia y nos permiten organizar el conocimiento sustantivo, pues están vinculados a la naturaleza de la historia como disciplina.

Las fuentes no hablan por sí mismas, el historiador las interpreta de cara a obtener respuestas a las preguntas formuladas. Por eso, en cuanto a la relación entre la evidencia y el conocimiento histórico, esta es inferencial, ya que la historia es una ciencia que estudia los "eventos que no son accesibles a nuestra observación", a partir de "algo que es accesible a nuestra observación" (Collingwood, 2001, p. 262). También Lee (2005) señala que cuando los estudiantes comienzan a operar con el concepto de evidencia como algo inferencial y ven el testimonio como proveedor de evidencia, la historia se convierte en una forma inteligible y potente de pensar sobre el pasado de forma autónoma. Sin embargo, Ashby (2006) recuerda que después de tres décadas de "trabajo crítico con las fuentes", la investigación en el Reino Unido sugiere que muchos estudiantes siguen revelando una "fuerte tendencia a tratar la información tal como ella es dada y de hacer llamamiento a las autoridades" (p. 153), aunque reconozcan que el conocimiento del pasado resulta en gran parte de los vestigios materiales. 
Estudios Pedagógicos XLIII, N 4: 203-227, 2017

CONSTRUYENDO UN APRENDIZAJE SIGNIFICATIVO A TRAVÉS DEL PATRIMONIO LOCAL: PRÁCTICAS DE EDUCACIÓN PATRIMONIAL EN PORTUGAL Y BRASIL

Cooper (2004) afirma que el aprendizaje activo y constructivista a través de la resolución de problemas ${ }^{2}$ permite a los estudiantes operar en experiencias propias y construcciones mentales, aprender a través de los sentidos, aplicar el aprendizaje a nuevos contextos mediante un desarrollo holístico: "emocional, social y cognitivo" (p. 56). Su estudio revela que el uso de estrategias de enseñanza-aprendizaje que implican experiencias con significado (como las visitas a los sitios y museos donde los niños pueden explorar y extrapolar), preguntas abiertas acerca de la evidencia (para permitir diferenciar entre saber, asumir y no saber), vocabulario seleccionado con diferentes niveles de abstracción y un ambiente de libre expresión son fundamentales para el desarrollo del pensamiento histórico de los estudiantes. Cooper (2004) señala que este trabajo debe comenzar temprano, porque los niños son capaces de operar con conceptos de validez y resolver problemas históricos cada vez más complejos, aprendiendo conceptos abstractos históricos al vincularlos con los concretos, por lo que no debe ser restringido a la repetición de información factual.

Otros autores añaden que, incluso si los estudiantes no siempre pueden establecer vínculos claros entre los restos materiales y las culturas que las produjeron, pueden reconocer que la observación cuidadosa de los artefactos conduce a mejores inferencias y a una historia más completa (Levstik, Henderson \& Schlarb, 2005).

Cainelli (2006) señala que la idea de trabajar con la observación de un objeto parte del presupuesto de que la observación directa de las huellas del pasado representado por las fuentes primarias hace que el estudiante, al manipular el objeto, reflexione sobre el pasado al que ha pertenecido este objeto.

En Estados Unidos, Levstik (2000) investigó las concepciones de estudiantes y profesores sobre significancia histórica a partir de imágenes, se eligieron las ocho más representativas y respondieron a algunas preguntas acerca de las opciones elegidas. Los resultados del estudio indicaron que los estudiantes y profesores se centraron en la versión oficial de la historia, revelando una imagen constante y de continuo progreso de la historia estadunidense, celebrando los eventos consensuales y las versiones estereotipadas del pasado. Además, concluyó que los maestros en sus clases evitan temas con los cuales se sienten menos confortables o que puedan perturbar a sus estudiantes, con el pretexto de no tener suficiente información para tratarlos de forma adecuada y objetiva, lo que la autora denomina "código de silencio" (p. 297). Así, Levstik (2000) advierte de los peligros de mantener estos silencios sobre ciertos aspectos del pasado, dejando que los estudiantes oscilen entre un nacionalismo autosatisfecho y una visión cínica de la historia, alejándolos de una participación ciudadana activa.

En otro estudio conjunto, Barton y Levstik (2008) señalan que es necesario que los estudiantes comprendan que la historia no siempre va hacia el bien común y el progreso, por lo que se debe exponerlos directamente a la complejidad y diversidad de perspectivas que siempre han existido: en clase se debe evitar reforzar las percepciones simplistas de los acontecimientos históricos, y antes mostrar que el pasado ha sido caracterizado por discordias y consensos, por retrocesos y avances, por restricciones y expansiones de oportunidades.

También Seixas (2002) reitera la necesidad de buscar la complejidad de la historia, ya que las respuestas deben incluir las opciones interpretativas involucradas en el uso de los

Relacionado con el Aprendizaje Basado en Problemas, método de enseñanza-aprendizaje centrado en el estudiante, en el que este adquiere competencias a través de situaciones de la vida real, y que pretende que el estudiante construya su conocimiento y, además, lo haga con el mismo proceso de razonamiento en situaciones nuevas en el futuro. 
vestigios del pasado para la construcción de los relatos históricos; reconocer la distancia entre presente y pasado, la complejidad y la incertidumbre; operar con múltiples causas, valores divergentes y diferentes perspectivas de los actores históricos. Estos criterios permiten distinguir entre intensificar la conciencia histórica y hacerla progresar. Seixas (2002) considera que las películas, la ficción histórica y ciertas actividades en los sitios históricos pueden ser muy útiles para intensificar la conciencia histórica, fomentar el interés y la imaginación, pero las escuelas están en mejor posición para hacerla progresar, orientando a los estudiantes en el difícil trabajo de mirar críticamente el pasado. En esta línea, Seixas y Clark (2004) y Nemko (2009) advierten que, para evitar una multitud de turistas históricos que no piensan críticamente sobre lo que observan, los profesores deben proponer tareas que lleven a los estudiantes a ser conscientes de los contextos en los que surgieron esos bienes patrimoniales.

La realización de actividades relacionadas con el patrimonio histórico y cultural de una comunidad puede fomentar el aprendizaje de los conceptos históricos, lo que implica no solo la comprensión de las situaciones del pasado presentadas por expertos, sino también la experimentación de procedimientos metodológicos (Ashby, Lee \& Shemilt, 2005) que permitan a los estudiantes la interpretación de fuentes históricas y patrimoniales diversas. Según el estudio europeo Youth and History (Angvik \& Borries, 1997), las fuentes históricas que los jóvenes europeos consideran más fiables son los museos lugares históricos y los documentos, aunque revelen más satisfacción por los primeros. Sin embargo, el aprendizaje más recurrente en sus clases de historia se centra en la dimensión factual (Pais, 1999).

Según Estepa y Cuenca (2006), debemos establecer criterios básicos para la inclusión del patrimonio en el currículo "partiendo de para qué educamos en patrimonio, qué formación patrimonial hemos de promover y cómo la desarrollamos y la evaluamos valoramos" (2006, p. 53).

En los últimos años, varios países europeos han modificado sus currículos escolares. Ha sido el caso de Portugal, pues en el 2012 se introdujeron cambios en los planes de estudio a través de las metas curriculares. Esto ha afectado también a la enseñanza de la historia y el tratamiento dado a la Educación patrimonial. Se ha constatado un desfase significativo entre el potencial didáctico del patrimonio para la enseñanza de la historia y su presencia en las directrices de los planes de estudio. En los documentos portugueses (así como en los españoles) subsiste una visión limitada y parcial de la Educación patrimonial (Pinto \& Molina, 2015). En Portugal, el documento Currículo Nacional do Ensino Básico -que ha estado vigente de 2001 a 2011- incluía referencias explícitas al contacto directo con fuentes patrimoniales afirmando que en la educación básica todos los estudiantes deben tener la oportunidad de experimentar actividades de aprendizaje de historia que impliquen, entre otros aspectos, el contacto estudio directo con patrimonio histórico y cultural nacional y regional local, sobre todo artístico, arquitectónico y arqueológico, a través de visitas de estudio trabajo de campo con carácter de colección, exploración y evaluación de datos.

Sin embargo, con la derogación del Currículo Nacional do Ensino Básico por el Despacho $N^{\circ}{ }^{\circ} 17169 / 2011$ de 23 de diciembre, las metas curriculares, mientras tanto elaboradas, han reforzado el papel de los contenidos que los estudiantes deberán aprender, presentando objetivos que implican en la mayoría de los casos operaciones relacionadas con la adquisición de la información y su integración.

No obstante, aunque los currículos portugueses incluyeron algunas referencias al estudio del patrimonio histórico y cultural, no atribuyen a la Educación patrimonial un área 
Estudios Pedagógicos XLIII, N 4: 203-227, 2017

CONSTRUYENDO UN APRENDIZAJE SIGNIFICATIVO A TRAVÉS DEL PATRIMONIO LOCAL: PRÁCTICAS DE EDUCACIÓN PATRIMONIAL EN PORTUGAL Y BRASIL

curricular específica. Si en el contexto actual no hay lugar a la integración de la Educación patrimonial como materia curricular autónoma -su transversalidad es en gran parte resultado de la heterogeneidad inherente al patrimonio: de lo material a lo intangible, de lo cultural a lo natural-, parece muy pertinente la aproximación a las fuentes patrimoniales en la enseñanza y el aprendizaje de la historia (Pinto, 2016).

En el caso de Brasil, la Educación patrimonial ha surgido en el seno de importantes discusiones sobre la necesidad de profundizar el conocimiento y la preservación del patrimonio histórico y cultural, en la secuencia del primer seminario sobre "El uso educacional de los museos y monumentos" en el Museo Imperial de Petrópolis, Río de Janeiro, en 1983. La Educación patrimonial ha sido enunciada como un proceso continuo y sistemático de trabajo educacional centrado en el patrimonio cultural como una fuente primaria de conocimiento individual y colectivo (Horta et al., 1999).

La Educación patrimonial establecida por el IPHAN (Instituto del Patrimonio Histórico y Artístico Nacional) en Brasil, pretende suscitar situaciones de aprendizaje sobre el proceso cultural y fundamentar, con los estudiantes, diferentes análisis sobre su propia vida personal y colectiva, constituyendo una "herramienta de alfabetización cultural que permite al individuo leer el mundo a su alrededor, llevándolo a comprender su universo socio-cultural y respectiva trayectoria histórico-temporal" (Horta et al., 1999, p. 34). Así, al proponer una metodología de Educación patrimonial no podemos olvidar las discusiones sobre los cambios en el espacio urbano, en los barrios e incluso en el sentido de pertenencia y de compartir costumbres y tradiciones heredadas.

La expresión Educación patrimonial, concebida como propuesta metodológica en forma de acción social, pretende analizar los bienes culturales como fuente histórica, conectando su acción en la vida práctica del individuo, recuperando las relaciones entre las generaciones, y promoviendo la apropiación de su herencia cultural por las comunidades y, más específicamente, por los estudiantes, en sistemas de educación formal y no formal (Horta et al., 1999). De este modo, la acción de Educación patrimonial del IPHAN ha sido estructurada en tres líneas de actuación: la inserción del tema Patrimonio Cultural en la educación formal, gestión compartida de las acciones educativas y establecimiento de marcos programáticos en el campo de la Educación patrimonial.

En el proceso de integración del patrimonio cultural en el contexto escolar, la Educación Patrimonial podrá promover un mejor aprendizaje sobre las cuestiones culturales, despertando el interés por conocer las identidades que asientan en las manifestaciones de la herencia cultural y de los lugares de memoria (Nora, 1997).

A través de actividades de Educación patrimonial, es posible analizar con los estudiantes las potencialidades de aproximación a un "monumento", o sea, "un edificio o sitio histórico de carácter ejemplar, por su significado en el curso de vida de una sociedad/comunidad y por sus características específicas de forma, estilo y función" (Horta et al., 1999, p. 14). En cierta medida, algunos edificios aislados, sitios o conjuntos edificados tienen un significado especial en la historia de Brasil, representando hitos en la trayectoria nacional. Otros tienen una importancia regional o local (Horta et al., 1999).

Es posible enseñar y aprender desde lo local a lo nacional y transnacional, analizando las fuentes locales como microcosmos. Además, la historia local posibilita explorar cuestiones acerca de la identidad y el proceso de investigación histórica (Cooper, 2002). Los profesores pueden realizar una enorme variedad de prácticas para promover no solo la comprensión del contexto histórico por los estudiantes, sino también la interpretación de fuentes diversas, 
incluyendo las patrimoniales, cuestionándolas críticamente. Así, los estudiantes pueden dar sentido al patrimonio como evidencia (Pinto, 2011) y no solo como simple ilustración. Por otra parte, las experiencias educativas de contacto directo con el patrimonio pueden promover sentimientos de pertenencia e involucrar a los jóvenes en la construcción de su conocimiento y de su acción presente y futura (Pinto, 2016). Los educadores tienen una responsabilidad particular en relación con este futuro común, contribuyendo al proceso de construcción por los jóvenes de identidades más abiertas e inclusivas.

Durbin, Morris y Wilkinson (1996) subrayan la importancia de incentivar en los estudiantes la observación de los signos que revelan el uso original y la función actual de los objetos, y reconocer que un objeto, aunque no sea valorado en una sociedad, puede serlo en otras, y asimismo tener un diferente significado social, religioso o político para diferentes individuos. Conocer el significado de un objeto implica comprender las personas que lo hicieron, utilizaron y conservaron; su estatuto, hábitos y comportamientos sociales; y otros aspectos de la tecnología, política y religión. En la enseñanza y el aprendizaje basado en objetos, a veces es más apropiado hacerlo en el aula y, en otras ocasiones, visitar sitios históricos y museos. Sin embargo, según estos autores estas visitas serán más fructuosas si los estudiantes ya han aprendido técnicas de análisis de objetos en el aula.

Hay una diversidad de miradas, de enfoques, que dan cuenta de la complejidad patrimonial y se están desarrollando líneas de investigación emergentes en Educación patrimonial (Fontal \& Ibañez-Etxeberria, 2017). La producción de materiales educativos para la interpretación del patrimonio se puede hacer de un modo puramente técnico o justificado en una investigación que establece objetivos, desarrolla modelos, los experimenta y evalúa.

En el ámbito de la Educación Histórica, esto implica que se entiendan los retos y las posibilidades de la enseñanza y del aprendizaje de la historia en un proceso en el que la relación maestro alumno no se conciba simplemente en la clase, sino que incluye el entorno en que viven, el conocimiento transmitido por su familia, su comunidad y los medios de comunicación de masas a que tienen acceso. También presupone que sobrepasen las afirmaciones de sentido común, pues la historia es una forma de conocimiento sistemático, con un conjunto específico de criterios con los que interpretar las fuentes y justificar la diversidad de perspectivas (de estudiantes y profesores, inclusive) sobre el pasado.

En síntesis, esto sugiere la interconexión de los enfoques teóricos y metodológicos de la Educación patrimonial y de la educación histórica. Nuestra intención es promover la reflexión sobre la práctica de la enseñanza, y sobre el aprendizaje, desde las narrativas de los estudiantes y sus perspectivas en las clases de historia, sea en el aula o en el entorno. Se pretende profundizar la comprensión del significado histórico de las experiencias y de las diferentes identidades culturales, así como del sentimiento de pertenencia o de distanciamiento hacia los bienes patrimoniales.

\section{PRÁCTICAS DE EDUCACIÓN PATRIMONIAL EN PORTUGAL Y BRASIL}

\subsection{MÉTODOS DE ESTUDIO}

A continuación, se presenta una síntesis sobre las investigaciones realizadas. El primer caso corresponde a un estudio de enfoque esencialmente cualitativo, basado en la teoría fundamentada (Strauss \& Corbin, 1998), que se ha desarrollado en el norte de Portugal 
Estudios Pedagógicos XLIII, N 4: 203-227, 2017

CONSTRUYENDO UN APRENDIZAJE SIGNIFICATIVO A TRAVÉS DEL PATRIMONIO LOCAL: PRÁCTICAS DE EDUCACIÓN PATRIMONIAL EN PORTUGAL Y BRASIL

(Pinto, 2011), con el objetivo de conocer la relación entre la evidencia y la conciencia histórica y patrimonial en cuanto a concepciones de estudiantes y profesores, con especial atención a la utilización de fuentes patrimoniales en la enseñanza y el aprendizaje de la historia, atendiendo a su relación con el proceso de construcción de significado del pasado (Pinto, 2016).

El estudio se ha sustentado en una reflexión en el ámbito de la psicología cognitiva y de la educación histórica, y ha intentado responder a tres cuestiones de investigación que han centrado el enfoque de la pesquisa (Pinto, 2011):

- ¿Cómo usan y dan sentido a los vestigios patrimoniales -espacios, edificios y objetos-, como evidencia de un pasado en cambio, los estudiantes portugueses de educación secundaria obligatoria cuando participan en actividades de aprendizaje fuera de la escuela?

- ¿Qué tipo de pensamiento histórico desarrollan esos estudiantes en un ambiente de exploración directa del patrimonio?

- ¿Qué concepciones revelan sus profesores de historia sobre la exploración del patrimonio en el contexto de actividades relacionadas con el uso de fuentes patrimoniales, en el ámbito del currículo escolar?

La muestra del estudio principal de esta investigación incluyó a 87 estudiantes -40 de $7^{\circ}$ grado (12/13 años) y 47 de $10^{\circ}$ grado (15/16 años)- en siete grupos acompañados de su maestro de historia, historia de la cultura y de las artes, de varias instituciones educativas de Guimarães, en el norte de Portugal.

Los instrumentos de recogida de datos utilizados han sido a) un "Cuestionario-guía" que propone a los estudiantes un conjunto de tareas escritas a partir de la observación directa y la interpretación de fuentes patrimoniales ubicadas en puntos específicos de un recorrido; b) dos breves cuestionarios para profesores (anteriores y posteriores a la actividad); c) entrevistas de seguimiento a 33 estudiantes, de cara a elucidar algunas de las respuestas escritas.

Se trató de elegir a un contexto histórico que fuera significativo a nivel local y nacional, en relación con el currículo de educación secundaria, y delinear una aproximación de educación histórica y patrimonial que constituyera un genuino desafío cognitivo para los estudiantes, integrando preguntas orientadoras, específicas y graduales, pero accesibles y motivadoras para ambos grupos (figuras 2,3 y 4). Se pretendía que tuvieran una idea de conjunto y no de objetos individuales o descontextualizados. Por eso se han incluido, en la primera página del cuestionario, las imágenes de un mapa antiguo de Guimarães y otro reciente (Figura 1) donde se registra el recorrido.

En el segundo caso, en Brasil, se investigó durante el 2015 y 2016 las narrativas de un grupo de estudiantes de $8^{\circ}$ grado de una escuela pública -Escola Estadual Padre João Tomes, en Três Lagoas, Mato Grosso do Sul- sobre los bienes patrimoniales y, específicamente, sobre la estación de ferrocarril de Noroeste de Brasil.

El método de Educación patrimonial seguido consistió en implementar acciones de enseñanza y aprendizaje basadas en la guía de Educación patrimonial definida por el IPHAN -presentando la estación del ferrocarril, en la ciudad de Três Lagoas como un edificio histórico y como un bien patrimonial local y regional-y también de la investigación en educación histórica (Barca, 2004). 
Estudios Pedagógicos XLIII, N 4: 203-227, 2017 CONSTRUYENDO UN APRENDIZAJE SIGNIFICATIVO A TRAVÉS DEL PATRIMONIO LOCAL: PRÁCTICAS DE EDUCACIÓN PATRIMONIAL EN PORTUGAL Y BRASIL

Figura 1. Primera página del cuestionario-guía con las cartas de Guimarães en el pasado y en el presente señalando el recurrido

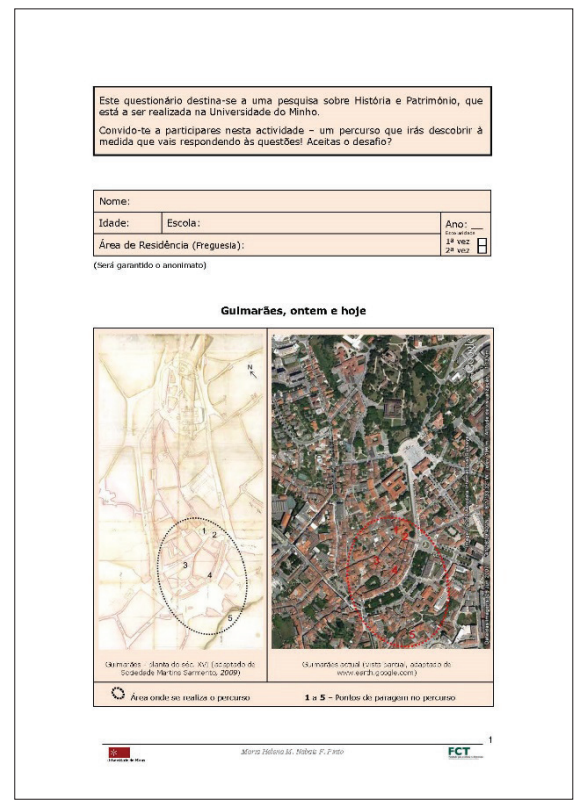

Fuente: Pinto (2011).

Figura 2. Página del cuestionario-guía de los estudiantes en el estudio principal

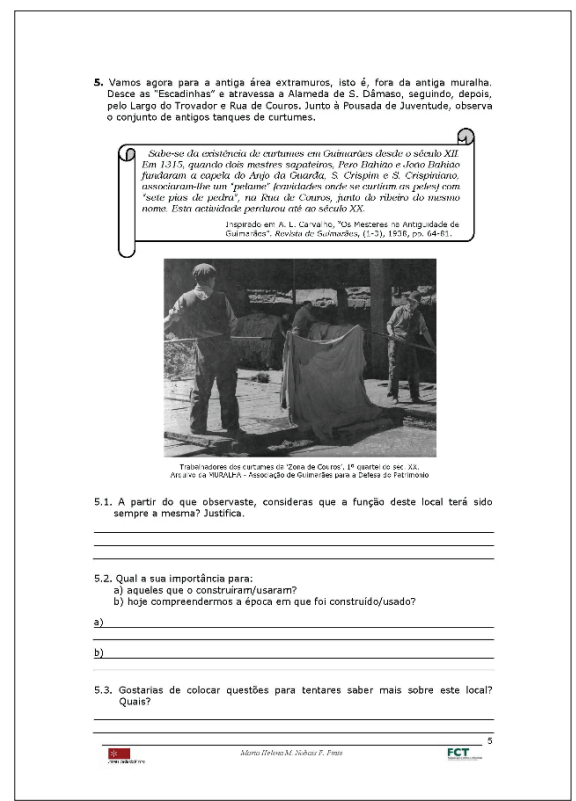

Fuente: Pinto (2011). 
Estudios Pedagógicos XLIII, N 4: 203-227, 2017

CONSTRUYENDO UN APRENDIZAJE SIGNIFICATIVO A TRAVÉS DEL PATRIMONIO LOCAL: PRÁCTICAS DE EDUCACIÓN PATRIMONIAL EN PORTUGAL Y BRASIL

Figura 3. Grupos de estudiantes de $7^{\circ}$ y $10^{\circ}$ grado realizando la actividad junto al Albergue de S. Crispim

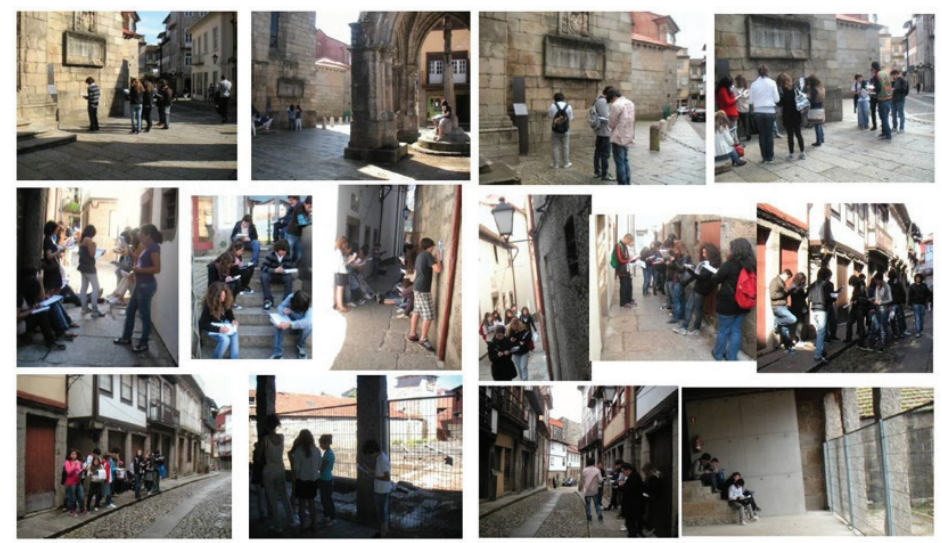

Fuente: Pinto (2011).

Figura 4. Antiguos tanques de curtiduría en la proximidad de la calle Couros, en Guimarães

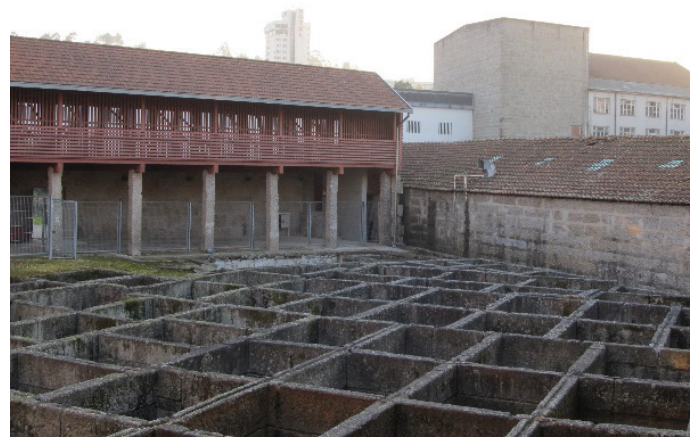

Fuente: Pinto (2011).

La investigación se ejecutó en dos etapas: la primera consistió en recoger imágenes de la estación en el archivo histórico municipal, y en la segunda se ha hecho el análisis de las imágenes con la participación de los estudiantes.

Se pretendía conocer, a partir de las narrativas de los estudiantes, sus perspectivas hacia a) los significados atribuidos al mundo presente y pasado; b) las ideas de cambio (progreso o decline lineal o complejo, dialéctica, ciclo, permanencias o roturas); c) el papel de la historia en la orientación temporal (relación entre pasado, presente y las expectativas de futuro) a nivel colectivo y a nivel individual (¿cómo se posiciona el individuo en la historia?); d) los valores de (inter)culturalidad en situación, de diálogo, de tensión o de conflicto (Barca, 2012). 
Atendiendo a la importancia de la historia y del patrimonio local, hemos recorrido el centro de la ciudad de Três Lagoas, identificando, a partir de la observación directa y del registro descriptivo, las diferencias entre los bienes culturales. La visita de campo con el método de pesquisa de Educación patrimonial puede estimular el desarrollo de las habilidades de observación de los estudiantes, de análisis crítico, de comparación y deducción, de formulación de hipótesis y resolución de problemas (Horta et al., 1999).

En el primer momento, el enfoque ha sido la historicidad de la estación de ferrocarril y su representación cultural en la ciudad. Los estudiantes analizaron la construcción de la estación y los cambios ocurridos en el edificio desde 1919 hasta la actualidad, además de reflexionar sobre los usos y la circulación de las personas en este espacio que, en cierta medida, ha sido presentado como propulsor de relaciones de interculturalidad en la región.

Entre las muchas imágenes recogidas, seleccionamos algunas que han marcado la historia de este bien patrimonial. Cabe señalar que después de la desactivación de la estación en la década de 1990, esta se ha convertido en objeto de enfrentamientos políticos, e incluso se ha insinuado su demolición.

El primer conjunto de imágenes (figuras 5 a 8) representa la estación de ferrocarril desde 1919 a mediados de 1940. A partir de las imágenes hemos discutido la construcción del ferrocarril, la interconexión entre los estados de São Paulo y Mato Grosso, posteriormente Mato Grosso do Sul, y el significado de la estación para los estudiantes en el contexto cultural y social de la ciudad y del estado.

Figura 5. Estación del ferrocarril "Noroeste do Brasil" en Três Lagoas, en 1919

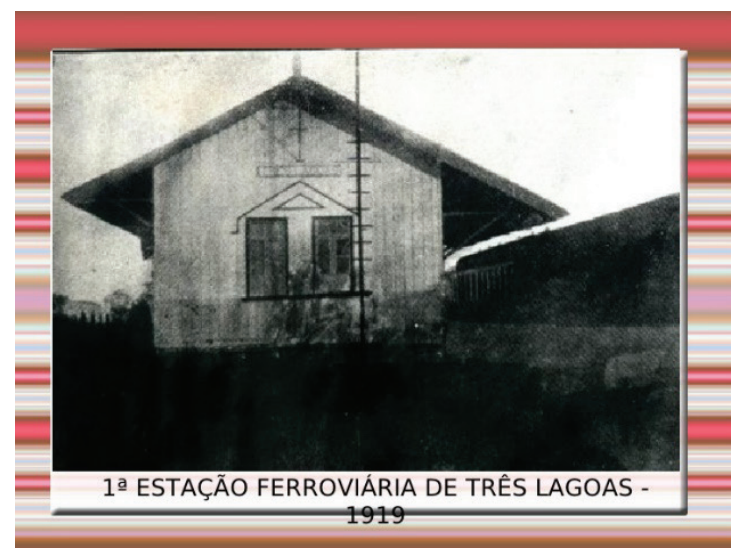

Fuente: Archivo de la Secretaria de Cultura, Zarbato (2015). 
Estudios Pedagógicos XLIII, N 4: 203-227, 2017

CONSTRUYENDO UN APRENDIZAJE SIGNIFICATIVO A TRAVÉS DEL PATRIMONIO LOCAL: PRÁCTICAS DE EDUCACIÓN PATRIMONIAL EN PORTUGAL Y BRASIL

Figura 6. Estación del ferrocarril "Noroeste do Brasil” en Três Lagoas, mediados de 1920

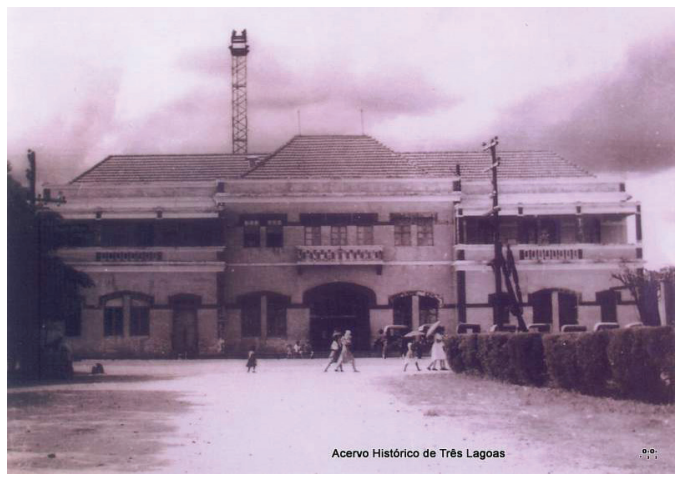

Fuente: Archivo de la Secretaria de Cultura, Zarbato (2015).

Figura 7. Antiguo vagón de la ferrovía "Noroeste do Brasil” en Três Lagoas, en 1932

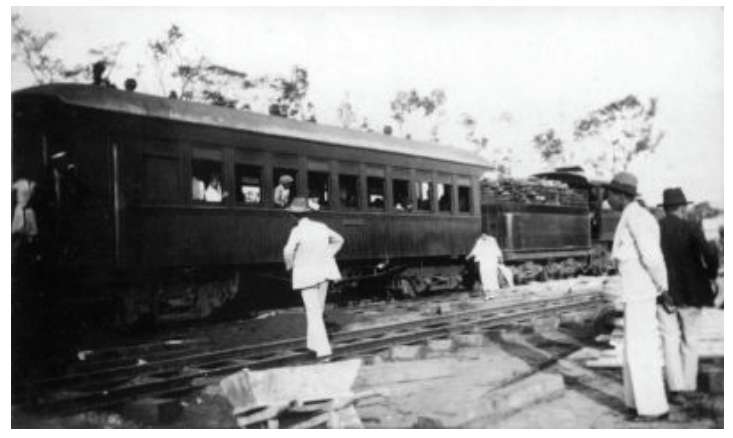

Fuente: Archivo de la Secretaria de Cultura, Zarbato (2015).

Figura 8. Ampliación de calles en el entorno de la Estación del ferrocarril en Três Lagoas, mediados de 1930

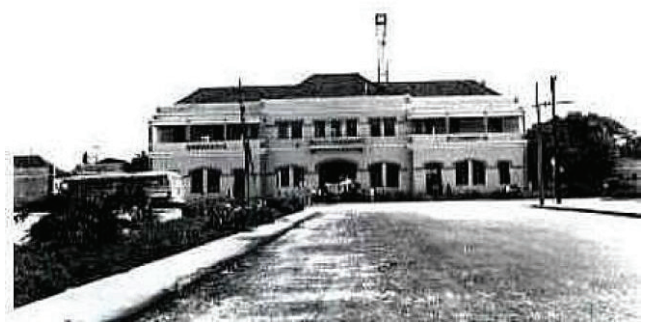

Fuente: Archivo de la Secretaria de Cultura, Zarbato (2015). 
El segundo conjunto de imágenes (figuras 9a y 9b) representa el periodo más reciente en que este bien patrimonial es objeto de controversias, y hay diferentes intenciones para el edificio. Sin embargo, hay un proyecto de la Secretaría de Cultura que pretende preservar el espacio como bien cultural, como testifica el Director de Cultura, Rodrigo Fernandes:

Pocos lugares tienen un conjunto de ferrocarril como el de Três Lagoas; hay edificios del inicio del siglo XX, como lo del vice-consulado de Portugal, que tiene una importancia sociopolítica fundamental para la ciudad. En él se defendieron los intereses de los trabajadores portugueses del ferrocarril Noroeste do Brasil, en Três Lagoas. Es un edificio construido en 1914, según el estilo neoclásico, con elementos característicos en la fachada, además de ser propiedad histórica y memorial de la ciudad. (Entrevista concedida a Caio Santos, 11/12/2015, trad. autoras).

A través de la narrativa del Director de Cultura, los estudiantes acceden a nueva información sobre diversas fuentes históricas respecto a la estación de ferrocarril como bien patrimonial y, al mismo tiempo, desarrollan la comprensión de este edificio en el contexto histórico de la ciudad.

La interpretación de la estación como bien patrimonial permite también la concientización sobre el proceso de pérdida de identidad de diversos espacios culturales e históricos en algunas ciudades brasileñas, lo que contribuye al silenciamiento y la "destruición" del bien patrimonial, como se puede observar en las imágenes (figuras 9a y 9b) presentadas abajo. Estas han sido utilizadas en el análisis histórico de los estudiantes sobre las transformaciones en la edificación, el entendimiento sobre el bien patrimonial y la reflexión sobre las representaciones culturales.

Figura 9a. Estación de ferrocarril de Três Lagoas en la actualidad

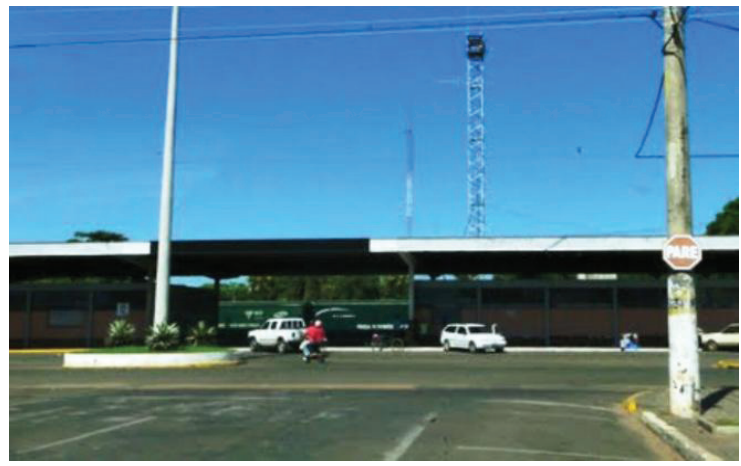

Fuente: Archivo de la Secretaria de Cultura, Zarbato (2015). 
Estudios Pedagógicos XLIII, N 4: 203-227, 2017

CONSTRUYENDO UN APRENDIZAJE SIGNIFICATIVO A TRAVÉS DEL PATRIMONIO LOCAL: PRÁCTICAS DE EDUCACIÓN PATRIMONIAL EN PORTUGAL Y BRASIL

Figura 9b. Estación de ferrocarril de Três Lagoas en la actualidad

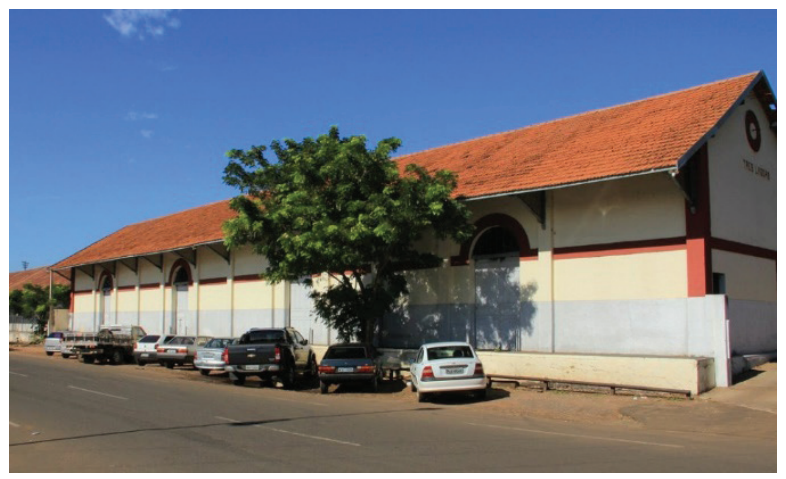

Fuente: Archivo de la Secretaria de Cultura, Zarbato (2015).

En la clase de historia (Figura 10) los estudiantes han reflexionado sobre la idea de relación entre las personas, y sobre los usos y los sentidos de patrimonio cultural. Los procedimientos han sido dialogar con los estudiantes sobre la permanencia, la valoración y el sentimiento de cada estudiante referente al patrimonio cultural como algo importante para narrar la historia. Se ha intentado comprender la forma en que esa relación ha influenciado la concepción de bien patrimonial e histórico en el pasado y en el presente.

Figura 10. Estudiantes de $8^{\circ}$ grado realizando actividad sobre patrimonio cultural de Três Lagoas

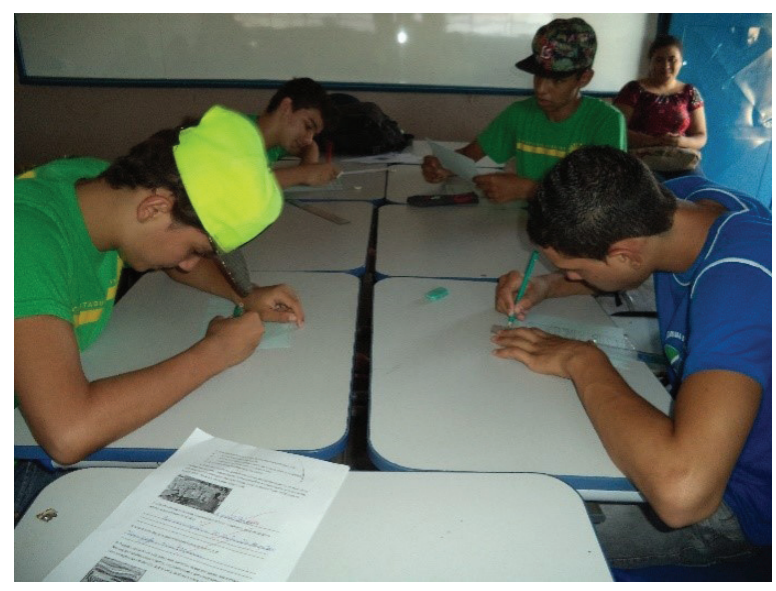

Fuente: Zarbato (2015). 


\subsection{ANÁLISIS DE DATOS}

En el estudio desarrollado en el norte de Portugal, el modelo conceptual de los estudiantes se ha basado en dos categorías que surgieron del análisis de datos:

- "Uso de la evidencia", las concepciones de los estudiantes respecto a cómo utilizan la información y hacen inferencias a partir de la "lectura" de las fuentes patrimoniales que se han organizado en cuatro niveles conceptuales: idea alternativa, inferencia sobre detalles concretos, inferencia a partir del contexto, y problematización.

- "Conciencia histórica", las concepciones de los estudiantes respecto al sentido que le otorgan a la relación entre pasado y presente, en términos de significado personal y social del patrimonio mediante la interpretación de las fuentes, se han organizado en cinco niveles conceptuales: conciencia a-histórica, conciencia de un pasado fijo, conciencia de un pasado simbólico, conciencia histórica emergente, y conciencia histórica explícita.

En este estudio también se ha investigado las concepciones de los profesores respecto al patrimonio y al uso de las fuentes patrimoniales en la enseñanza ${ }^{3}$, pero por razones de espacio y de ámbito de este texto, más centrado en el aprendizaje de los estudiantes, se presentan aquí dos resultados del análisis de las respuestas de los estudiantes. Empezamos por algunos ejemplos relativos al uso de la evidencia:

a. Idea alternativa. Algunos estudiantes revelan ideas imprecisas o confusas sobre el objeto o edificio, o reproducen ideas de sentido común:

Creo que la persona que la hizo [la inscripción conmemorativa], y la puso en la iglesia, quiso mostrar su trabajo a los que desean saber. (Alcina, $7^{\circ}$ grado, 13 años)

El 'loudel' se parece a una especie de ropón, parece ser cómodo. (Fausto, $10^{\circ}$ grado, 16 años).

b. Inferencia a partir de detalles concretos. La mayoría de los estudiantes considera que las fuentes escritas y patrimoniales proporcionan información directa, por eso las descripciones e interpretaciones son superficiales y sus conjeturas se refieren a detalles factuales o funcionales:

Un rey ordenó la construcción de esta iglesia. (Conceição, $7^{\circ}$ grado, 12 años).

La casa no tiene la misma función que antes, porque en la placa está escrito "viejo albergue-hospital”. Más tarde se convirtió en albergue de San Crispíncon la cena de Nochebuena-. (Anabela, $10^{\circ}$ grado, 17 años).

\footnotetext{
Se intentó comprender cómo los profesores -mediadores entre las fuentes históricas y su interpretación por los alumnosconciben la contribución de la exploración de fuentes patrimoniales en el aprendizaje de la historia por los alumnos, qué tipos de conciencia revelan en relación con ese proceso de desarrollo del pensamiento histórico de los alumnos y las conexiones que estos pueden establecer entre identidad y patrimonio en cuanto a la orientación temporal. En lo referente a las concepciones de los profesores sobre la utilización de fuentes patrimoniales se observó el predominio del perfil conceptual "conexión de fuentes en contexto" sobre los restantes. Con respecto a las finalidades de la enseñanza y divulgación del patrimonio, en la dimensión aprendizaje predominaron los perfiles "consolidación del conocimiento" y "construcción del conocimiento"; en la dimensión conciencia histórica se pone de relieve el perfil "conocimientos en contexto", y en lo referente a la dimensión conciencia patrimonial se destacó el perfil "sentido de identidad local".
} 
Estudios Pedagógicos XLIII, N 4: 203-227, 2017

CONSTRUYENDO UN APRENDIZAJE SIGNIFICATIVO A TRAVÉS DEL PATRIMONIO LOCAL: PRÁCTICAS DE EDUCACIÓN PATRIMONIAL EN PORTUGAL Y BRASIL

c. Inferencia a partir del contexto. Varios estudiantes contextualizan la información en un conjunto más amplio de conocimientos previos, y las respuestas revelan inferencias personales basadas en esos conocimientos, encuadrando la información en secuencia de tiempo, o estableciendo algún lazo con el contexto político, social y económico:

Veo que es una vestimenta militar y parece tener sangre en él. (Fabio, $7^{\circ}$ grado, 12 años).

Cuando comparo con el otro objeto este tiene más decoración, símbolos portugueses en las flores y en los bordes con decoración vegetalista, tiene escritura gótica y la otra es del siglo XVII. (Plácido, $10^{\circ}$ grado, 15 años).

Me pregunto cuáles serían los pensamientos de los sastres en el momento en que hacían la vestimenta. (Vasco, $7^{\circ}$ grado, 12 años).

d. Problematización. Algunas de las respuestas revelan inferencias personales que cuestionan el contexto en términos de evidencia y relaciones de tiempo, o ubicando hipótesis respecto a diversas posibilidades, o articulando elementos políticos, sociales y económicos en el mismo contexto, o incluso haciendo conjeturas sobre varios contextos en términos de relaciones de tiempo:

¿Qué tipo de materiales se utilizaron en este hospital?, ¿Qué necesidades tenían estos hombres?, ¿Habrán tomado parte en la guerra, ayudando a los nobles y al rey? (Alexandra, $10^{\circ}$ grado, 15 años).

¿Cuál era el significado de una iglesia para la gente de ese período, se construyeran una iglesia y no un centro comercial? Hoy en día esto sucedería. (Isaura, $7^{\circ}$ grado, 12 años).

En seguida se refieren también algunos ejemplos relativos a las concepciones de los estudiantes en cuanto a conciencia histórica:

e. Conciencia a-histórica. A un nivel menos elaborado, algunas respuestas no mencionan ningún tipo de 'significancia' o revelan ideas estereotipadas:

Transmitir un mensaje, o sus pensamientos. (Adelina, $7^{\circ}$ grado, 12 años).

Fue interesante, agradable. Hemos caminado mucho. (Plinio, $7^{\circ}$ grado, 13 años).

f. Conciencia de un pasado fijo. Muchos estudiantes evalúan las acciones de la gente del pasado según los valores actuales, otros perciben el pasado en términos genéricos, como intemporal, y la mayoría concibe el pasado como imagen del presente con miras a la adquisición de conocimientos:

Se utiliza para albergar a los peregrinos y la gente pobre. Todavía lo hacemos hoy en día. (Plácido, $10^{\circ}$ grado, 15 años).

Dejar el registro de algunos momentos o eventos importantes. (Bianca, $7^{\circ}$ grado, 13 años).

g. Conciencia de un pasado simbólico. La forma como el patrimonio prevaleció hasta nuestros días y su preservación se entienden en función de su significado de evocación de los principales acontecimientos del pasado (Rüsen, 2004; Seixas \& Clark, 2004), o por su significado en términos de identidad local o nacional. Algunos estudiantes valoran el patrimonio porque evoca un "pasado de oro", otros se refieren al pasado como un modelo para el presente, expresando una relación emocional entre la identidad y el patrimonio local: 
Querían mostrar su obra monumental y en honor a "Santa María da Oliveira". Debido a esta ser una "era dorada" de nuestra comunidad, y creo que la gente siempre mira el pasado. (Irene, $7^{\circ}$ grado, 12 años).

Este lugar fue construido con solidez y se ha conservado durante mucho tiempo, y era importante para los que trabajan aquí porque era un símbolo de sus antepasados. (Denise, $10^{\circ}$ grado HCA, 17 años).

h. Conciencia histórica emergente. La relación entre el pasado y el presente se entiende de una manera lineal con respecto al uso y función de las fuentes patrimoniales y las características socio-económicas relacionadas con el pasado o el presente. Sin embargo, varias respuestas revelan una orientación temporal emergente, conectando contextualización y ritmos de cambio diversos:

Fue construida por sus fundadores, dos zapateros que lo han utilizado en su trabajo con los cueros, supongo. (Augusta, $10^{\circ}$ grado, 15 años).

Los viejos métodos ayudan a desarrollar nuevas técnicas y a comprender la forma en que solían vivir en el pasado. Los habitantes también pueden adquirir conocimientos sobre la vida pasada en Guimarães. (Pascoal, $7^{\circ}$ grado, 13 años).

i. Conciencia histórica explícita. Algunas respuestas argumentan históricamente en función de la relación entre contextos sociales, económicos, políticos, religiosos y culturales, reconociendo la dualidad cambio/continuidad en la relación pasadopresente-futuro. Un grupo más limitado de respuestas ha revelado una conciencia de la historicidad de las fuentes patrimoniales, reconociendo su interpretación contextualizada como esencial para la comprensión histórica:

La ciudad conserva importantes vestigios que nos ayudan a entender el curso de la vida en Guimarães durante los siglos XIV y XV. También se reconoce que la vida era entonces bastante organizada en Guimarães. (Daniel, $10^{\circ}$ grado, 18 años).

Fue importante porque producía cuero para el comercio y sostenía también la capilla y el albergue. Todo está conectado aquí. (Isaura, $7^{\circ}$ grado, 12 años).

En el estudio desarrollado en Três Lagoas, Mato Grosso do Sul, Brasil, las concepciones de los estudiantes que emergieron del análisis de los datos revelaron algunas inquietudes que impulsaron la investigación. Efectivamente, se percibe que algunos estudiantes tienen concepciones sobre patrimonio cultural relacionadas con las memorias de valoración de la región en que viven. Además, los estudiantes se han involucrado en las actividades de visita al patrimonio y empezaron o ampliaron el entendimiento de que la historia puede ser contada a partir de las edificaciones, de los múltiples elementos culturales, y que estos pertenecen a los diversos grupos sociales que conviven en la ciudad.

Las narrativas de los estudiantes se concentraron en algunas cuestiones importantes relacionadas con el contexto histórico y a las cuales se hace referencia en los ejemplos siguientes:

Yo vivo en el barrio de Santa Luzia, crecí con mi abuelo hablando de la estación y de cómo era importante para irse a Campo Grande y a otras regiones. Me acabo de dársele importancia cuando lo empezamos a estudiar la clase de historia, porque he visto que muchas cosas han sucedido en la estación. (Carol, $8^{\circ}$ grado, 13 años).

Cuando empezó la discusión sobre la demolición de la estación yo me quedé muy triste porque tengo clase de teatro en una de sus habitaciones. (Vinicius, $8^{\circ}$ grado, 14 años). 
Estudios Pedagógicos XLIII, N 4: 203-227, 2017

CONSTRUYENDO UN APRENDIZAJE SIGNIFICATIVO A TRAVÉS DEL PATRIMONIO LOCAL: PRÁCTICAS DE EDUCACIÓN PATRIMONIAL EN PORTUGAL Y BRASIL

Me he dado cuenta de que hay muchas historias relacionadas con lo que ocurrió en la estación, que ha sido una parte importante de la ciudad, para el trabajo, para el paseo, y en la actualidad su historia no es relatada. (Claudia, $8^{\circ}$ grado, 14 años). Cuando les dije a mis tíos que iba a investigar la estación en la clase de historia, me dijeron varios nombres de los trabajadores que actualmente están luchando para que no sea demolida, y eso para mí es valorar la historia. (Lucia, $8^{\circ}$ grado, 13 años).

Estas narrativas posibilitaron conocer mejor las concepciones históricas de presente y pasado, así como las ideas de los estudiantes sobre la preservación, conservación e identificación de los bienes patrimoniales locales, además del interés hacia este enfoque en la historia de su comunidad y región.

La intención de involucrar a los estudiantes en todo el proceso de enseñanza trajo algunas importantes contribuciones a la clase de historia: fue posible percibir las dificultades de los estudiantes al momento de interpretar las fuentes históricas, en leer los cambios presentados en las imágenes y narrar el proceso del patrimonio cultural en la ciudad.

Las respuestas de los estudiantes revelan diferentes "miradas" sobre las experiencias de aprendizaje con respecto a la historia de su ciudad, reportando las continuidades y los cambios en el entorno urbano. De esta forma se construye la memoria histórica, partiendo de la pesquisa e interpretación, para la orientación temporal. Partiendo de la observación de las fuentes, y especialmente del patrimonio histórico, durante la visita interpretaron históricamente las modificaciones en el espacio urbano, así como las formas de valoración de diferentes tipos de patrimonio. La orientación temporal asume importancia en la construcción de la narrativa de cada estudiante, pues en general percibieron el patrimonio cultural como elemento histórico, y revelaron conciencia respecto a la preservación de los bienes patrimoniales.

\section{CONCLUSIONES}

En la actualidad, la Educación patrimonial se utiliza para complementar el plan de estudios vigente; sin embargo, los resultados de varios estudios (Fontal \& Ibáñez-Etxeberria, 2017) sugieren que esta sea incluida no solo en las experiencias de aprendizaje de los estudiantes, sino que también en el plan de estudios nacional.

En el ámbito de la investigación en educación -con enfoque en patrimonio, historia y ciencias sociales- ha sido nuestra intención percibir cómo, en dos países diferentes, la implementación de actividades de exploración del patrimonio cultural favorece la progresión en el conocimiento histórico y en la conciencia patrimonial de los estudiantes, sin olvidar que las cuestiones de la historia y de la Educación patrimonial tienen repercusiones en temas de la ciudadanía, lo que implica reconocer que, como ciudadanos, tenemos el derecho a la memoria, pero también el deber de contribuir al mantenimiento del valioso acervo cultural del país (Oriá, 2005), comprendiéndolo como una construcción con múltiples contribuciones.

La atribución de sentido y significado al patrimonio material e inmaterial justifica en gran parte la articulación entre Educación patrimonial y enseñanza de la historia, pues la primera contribuye para integrar la historia local y participar en el proceso de reconocimiento e valoración del patrimonio. No obstante, hay que tener presente el carácter 
polimórfico del hecho patrimonial, que resulta de construcciones y selecciones complejas, de contingencias varias que rodean su uso, tanto pasado como presente, y, por eso mismo, su investigación debe ser situada para ser significativa.

Los estudios aquí presentados y desarrollados en contextos diferentes, si bien sin propósitos comparativos, muestran que hay potencial para la interpretación de las fuentes patrimoniales en la educación. Sin embargo, los resultados obtenidos también nos advierten de obstáculos y limitaciones a enfrentar con propuestas creíbles para el desarrollo de la Educación patrimonial, particularmente en el ámbito formal. Así, del estudio de las concepciones de alumnos, y también de los profesores, hay que pasar a la acción con el fin de aproximarnos a lo que ocurre en el aula cuando se enseña patrimonio: qué contenidos patrimoniales se seleccionan, qué actividades se realizan, qué interacciones se establecen con el alumnado y con los museos y sus materiales didácticos. Por fin, la enseñanzaaprendizaje de la historia, y de las ciencias sociales en general, también podría enriquecerse con formación continua de profesorado en el ámbito de Educación patrimonial.

Los documentos curriculares no individualizan los contenidos de la historia local, pero señalan conexiones posibles en las situaciones de aprendizaje, dejando a la discreción de los profesores su aplicación. Sin embargo, muchos profesionales de educación nunca han tenido contacto previo (ni formación específica) con metodologías de enseñanza en estas áreas. Sería importante que se reflexione más, y de forma sistemática, acerca de qué y cómo aprenden los estudiantes en sus clases, cómo se relacionan con el pasado a través de la interpretación de sus huellas que constituyen interesantes fuentes históricas.

Utilizar fuentes patrimoniales, de carácter material o inmaterial, en actividades educativas puede ayudar a crear conciencia histórica en los jóvenes, permitiéndoles comprender mejor y valorar la historicidad del pasado y del presente de su comunidad, y además construir críticamente su identidad personal y social. Asimismo, al ubicarse la enseñanza-aprendizaje del patrimonio en el planteamiento del currículo de la historia y de las ciencias sociales, se contribuye también a la formación ciudadana de los estudiantes.

Estimular a los jóvenes a pensar y discutir sobre diferentes versiones del pasado concretamente cuando los edificios y sitios se analizan críticamente- puede contribuir a una mejor educación en una sociedad donde el diálogo entre diferentes culturas debe fortalecerse. Lo más adecuado es proporcionar tareas que puedan cuestionar las preconcepciones de los estudiantes y fomentar la interpretación histórica de las fuentes patrimoniales en términos de historia local -relacionándola con la historia nacional y de carácter más amplio- de cara a desarrollar un aprendizaje contextualizado y significativo.

\section{REFERENCIAS BIBLIOGRÁFICAS}

Andrade, A. (1993). Conhecer e nomear: a toponímia das cidades medievais portuguesas. A Cidade. Jornadas Inter e Pluridisciplinares. Universidade Aberta, 121-140.

Angvik, M., \& Borries B. (1997). Youth and History: a comparative European survey on historical consciousness and political attitudes among adolescents. Hamburg: Körber-Stiftung.

Ashby, R. (2006). Desenvolvendo um conceito de evidência. Educar em revista, número especial, 151-170.

Ashby, R., Lee, P., \& Shemilt, D. (2005). Putting principles into practice: teaching and planning. In M. S. Donovan \& J. D. Bransford (Eds.), How students learn: History in the classroom (pp. 79- 
Estudios Pedagógicos XLIII, N 4: 203-227, 2017

CONSTRUYENDO UN APRENDIZAJE SIGNIFICATIVO A TRAVÉS DEL PATRIMONIO LOCAL: PRÁCTICAS DE EDUCACIÓN PATRIMONIAL EN PORTUGAL Y BRASIL

178). Washington DC: The National Academies Press.

Ausubel, D., Novak, J., \& Hanesian, H. (1978). Educational Psichology: a cognitive view. New York: Holt, Rinehart and Winston.

Barca, I. (2004). Aula Oficina: do projecto à avaliação. In I. Barca (Org.), Para uma educação histórica de qualidade. Actas das IV Jornadas Internacionais de Educação Histórica (pp. 131144). Braga: Universidade do Minho.

Barca, I. (2012). Ideias chave para a educação histórica: uma busca de (inter)identidades. História Revista, 17(1), 37-51.

Barton, K., \& Levstik, L. (2008). "It wasn't a good part of history": National Identity and students' explanations of historical significance. In L. Levstik \& K. Barton (Eds.), Researching history education: theory, method, and context (pp. 240-272). New York: Taylor and Francis.

Cainelli, M. (2006). Educação Histórica: perspectivas de aprendizagem da história no ensino fundamental. Educar em revista, número especial, 57-72.

Catroga, F. (2009). Os passos do homem como restolho do tempo: memória e fim do fim da história. Coimbra: Almedina.

Choay, F. (2000). A Alegoria do Património. Lisboa: Edições 70.

Colardelle, M. (1998). Les acteurs de la constitution du patrimoine: travailleurs, amateurs, professionnels. In J. Le Goff (Coord.), Patrimoine et Passions Identitaires. Actes des Entretiens du Patrimoine (pp. 123-135). Paris: Fayard.

Collingwood, R. (2001). A ideia de História (9a ed.). Lisboa: Editorial Presença.

Cooper, H. (2002). Didáctica de la Historia en la educación infantil y primaria. Madrid: Morata.

Cooper, H. (2004). O pensamento histórico das crianças. In I. Barca (Org.), Para uma Educação Histórica de qualidade. Actas das Quartas Jornadas Internacionais de Educação Histórica (pp. 55-74). Braga: CIEd, Universidade do Minho.

Durbin, G., Morris, S., \& Wilkinson, S. (1996). Learning from objects: a teachers' guide. London: English Heritage.

Estepa, J., \& Cuenca, J. (2006). La mirada de los maestros, profesores y gestores del patrimonio. Investigación sobre concepciones acerca del patrimonio y su didáctica. In R. Calaf \& O. Fontal (Eds.), Miradas al patrimonio (pp. 51-71). Gijón: Ediciones Trea.

Ferreira, M. C. F. (2010). Guimarães: 'duas vilas, um só povo'. Estudo de história urbana (12501389). Braga: CITCEM.

Fontal, O., \& Ibáñez-Etxeberria, A. (2017). La investigación en Educación Patrimonial. Evolución y estado actual a través del análisis de indicadores de alto impacto. Revista de Educación, 375(1), 84-214.

Halbwachs, M. (1990). A memória coletiva. São Paulo: Edições Vértice.

Hartog, F. (2005). Time and Heritage. Museum International, 227, 7-18.

Horta, M. L. P., Grunberg, E., \& Monteiro, A. Q. (1999). Guia Básico de Educação Patrimonial. Brasília: IPHAN/Museu Imperial.

IPHAN. (2014). Patrimônio Cultural. Instituto do Patrimônio Histórico e Artístico Nacional. Retirado de http://portal.iphan.gov.br/pagina/detalhes/218.

Lee, P. (2005). Putting principles into practice: understanding history. In M. S. Donovan \& J. D. Bransford (Eds.), How students learn: history in the classroom (pp. 31-77). Washington, DC: The National Academies Press.

Levstik, L. (2000). Articulating the silences: teachers and adolescents' conceptions of historical significance. In P. Stearns, P. Seixas \& S. Wineburg (Eds.), Knowing, teaching, and learning history: national and international perspectives (pp. 284-305). New York: New York University Press.

Levstik, L., Henderson, A., \& Schlarb, J. (2005). Digging for clues: an archaeological exploration of historical cognition. In R. Ashby, P. Gordon \& P. Lee (Eds.), Understanding history: recent research in History Education (pp. 37-53). London: Routledge Falmer. 
Lowenthal, D. (1999). The past is a foreign country. Cambridge: Cambridge University Press.

Lowenthal, D. (2003). Heritage crusade and the spoils of History. Cambridge: Cambridge University Press.

Mendonça, N. R. (1991). A (des)construção das (des)ordens: poder e violência em Três Lagoas, 1915-1945 (Tese Doutorado em História). Faculdade de Filosofia, Letras e Ciências Humanas da USP, São Paulo.

Nemko, B. (2009). Are we creating a generation of 'historical tourists'? Visual assessment as a means of measuring pupils' progress in historical interpretation. Teaching History, 137, 32-39.

Nora, P. (1997). Mémoire et Histoire. In P. Nora (Dir.), Les Lieux de Mémoire: la République, la Nation, les France (pp. 23-43). Paris: Gallimard.

Oriá, R. (2005). Ensino de História e diversidade cultural: desafios e possibilidades. Cadernos Cedes, 25(67), 378-388.

Pais, J. M. (1999). Consciência histórica e identidade: os jovens portugueses num contexto europeu. Oeiras: Celta Editora.

Pinto, H. (2011). Educação histórica e patrimonial: conceções de alunos e professores sobre o passado em espaços do presente (Tese de doutoramento em Ciências da Educação). Universidade do Minho, Portugal.

Pinto, H. (2016). Construcción de identidades y conciencia patrimonial: el papel de la educación patrimonial en Portugal. In S. Molina, N. Llonch \& T. Martinez (Eds.), Identidad, ciudadanía y patrimonio. Educación histórica para el siglo XXI (pp. 17-38). Gijón: Ediciones Trea.

Pinto, H., \& Molina, S. (2015). La educación patrimonial en los currículos de ciencias sociales en España y Portugal. Educatio Siglo XXI, 33(1), 103-128. doi:10.6018/j/210951

Pomian, K. (1998). Conclusion de la journée du 6 janvier. In J. Le Goff (Coord.), Patrimoine et Passions Identitaires. Actes des Entretiens du Patrimoine (pp. 109-117). Paris: Fayard, Éditions du Patrimoine.

Ricoeur, P. (2000). La mémoire, l'histoire, l'oubli. Paris: Éditions du Seuil.

Rüsen, J. (2001). Razão histórica. Teoria da História: os fundamentos da ciência histórica. Brasília: Editora UnB.

Rüsen, J. (2004). Historical Consciousness: narrative structure, moral function, and ontogenetic development. In P. Seixas (Ed.), Theorizing Historical Consciousness (pp. 63-85). Toronto: University of Toronto Press.

Rüsen, J. (2014). Cultura faz sentido: orientações entre o ontem e o amanhã (Trad. Nélio Schneider). Petrópolis: Vozes.

Sampaio, A., \& Meira, J. (1991). Relatório da Exposição Industrial de Guimarães em 1884. Guimarães: Muralha, Associação de Guimarães para a Defesa do Património.

Seixas, P. (2002). The Purposes of Teaching Canadian History. Canadian Social Studies, 36(2).

Seixas, P., \& Clark, P. (2004). Murals as monuments: students' ideas about depictions of civilization in British Columbia. American Journal of Education, 110(2), 146-171.

Strauss, A., \& Corbin, J. (1998). Basics of qualitative research: techniques and procedures for developing Grounded Theory. Thousand Oaks: Sage.

Yánez Casal, A. (1999). Património e modernidade. Museologia e Autarquias (pp. 57-61). Tondela: Câmara Municipal de Tondela.

Zarbato, J. (2015). Ensino de História, Patrimônio Cultural e currículo: reflexões sobre ações educativas em Educação patrimonial. Revista Labirinto, Ano XV(22), 77-90.

Zarbato, J., \& Santos, C. (2015). Relatório Parcial de pesquisa. Anápòlis: PROPP/UFMS. 
